Indústria e Desenvolvimento Econômico:

desafios e perspectivas

18 a 20 de setembro de 2018

Uberlândia - Minas Gerais

\title{
OS PRIMEIROS IMPACTOS DA INDÚSTRIA 4.0 SOBRE O SETOR DE PAPEL E
}

CELULOSE

\author{
Sarah Cristina Ribeiro Ferreira \\ Graduanda em Ciências Econômicas pela Universidade Federal de Uberlândia \\ sarahcristina_rf@hotmail.com

\section{Germano Mendes de Paula} \\ Professor Titular da Universidade Federal de Uberlândia \\ germano@ufu.br
}

RESUMO: O objetivo deste artigo é analisar os impactos da Indústria 4.0 no setor de papel e celulose. A metodologia aplicada consiste na identificação de oito clusters tecnológicos e seus primeiros efeitos sobre o setor, sendo estes internet das coisas, produção inteligente e conectada, inteligência artificial, tecnologias de redes, biotecnologia e bioprocessos, nanotecnologia, materiais avançados e armazenamento de energia. Também foram aplicados questionários para a identificação da influência dessas inovações sobre a realidade brasileira. Os resultados apresentados demonstram a difusão e importância atribuídas a essas tecnologias no setor em 2017, em 2022 e em 2027.

Palavras-chave: Indústria 4.0, Papel e Celulose, Inovação.

ABSTRACT: The purpose of this paper is to analyze the impacts of Industry 4.0 on the pulp and paper sector. The applied methodology consists in the identification of eight technological clusters and their first effects on the industry: internet of things, internet of things, intelligent and connected production, artificial intelligence, networking technologies, biotechnology and bioprocesses, nanotechnology, advanced materials and energy storage. Questionnaires were also applied to identify the influence of these innovations on the Brazilian reality. The results demonstrate the diffusion and importance attributed to these technologies in the sector in 2017, in 2022 and in 2027.

Key words: Industry 4.0, Pulp and Paper, Innovation

Classificação JEL: O33

Área temática: 1.6 Novos temas - Indústria 4.0, Internet das coisas 


\section{INTRODUÇÃO}

A partir da primeira revolução do século XVIII, houve a transição para um novo método de produção baseado em processos mecanizados, propiciando aumento de produtividade. Desde a década de 1970, houve evolução das tecnologias da informação e da comunicação (TIC) e sua integração nos processos produtivos trazendo benefícios às cadeias de valor. $\mathrm{O}$ desenvolvimento das tecnologias impulsionou a produtividade industrial, reduzindo custos de produção e fornecendo soluções para o relacionamento com fornecedores e clientes por meio de novos modelos de negócios (SANTOS et. al, 2018).

No entanto, o progresso tecnológico em um cenário com maior complexidade, demanda uma nova lógica de organização industrial, apresentada por intermédio da Indústria 4.0, cuja principal característica é a integração dos sistemas virtuais e físicos nos processos produtivos (SANTOS et. al, 2018, p. 113). Diferente da organização anterior que focalizava na automação de máquinas e processos, a Indústria 4.0 abrange um conjunto de tecnologias de ponta ligadas à Internet com a finalidade de tornar os sistemas produtivos mais colaborativos e flexíveis, mediante a digitalização de todos os ativos físicos e integração de ecossistemas digitais em toda a cadeia de valor para proporcionar eficiência de custo e bens de maior qualidade.

A indústria de base florestal vivenciou as três fases anteriores da transformação industrial, a contar pela criação da energia a vapor até a elétrica, passando pela integração progressiva das tecnologias de automação e informação. Assim, acompanha as inovações próprias a Indústria 4.0, em um contexto de evolução das necessidades dos clientes e dos mercados, juntamente com as pressões relacionadas à concorrência global (MARTIN, 2017).

Com o objetivo de entender os primeiros impactos da Indústria 4.0 no setor de celulose e papel mundial e nacional, este artigo é estruturado em quatro seções, excluindo esta sucinta introdução. A primeira aborda as novas tecnologias da Indústria 4.0, enquanto a segunda aborda como opera o sistema produtivo de Papel e Celulose (P\&C). Por sua vez, a terceira tem como objetivo examinar a maneira com que as tecnologias inerentes a Indústria 4.0 se aplicam ao setor de $\mathrm{P} \& \mathrm{C}$ e os primeiros impactos que essa revolução desperta no Mundo e no Brasil. Assim, a metodologia aplicada consiste em uma revisão aplicada sobre a Indústria 4.0 para o setor de celulose e papel utilizando a classificação de clusters tecnológicos empregada pelo IEL (2017). A quarta e última seção sintetiza as principais conclusões do artigo. 


\section{A INDÚSTRIA 4.0 E SEUS PRINCIPAIS CLUSTERS TECNOLÓGICOS}

A Indústria 4.0 é caracterizada pela integração das cadeias de valor, digitalização de produtos e serviços e pelos modelos de negócios digitais e acesso ao cliente. Desta forma, há a integração dos processos verticalmente em toda a organização, desde o desenvolvimento, a compra de insumos, a fabricação, logística, até a criação de novos produtos e serviços digitalizados, fornecendo soluções digitais personalizadas e serviços completos, orientados por dados e sistemas de plataforma integrada (SANTOS et. al, 2018).

Essa nova revolução é caracterizada por oito inovações disruptivas que impactarão indústria nos próximos anos, constituindo-se por Internet das Coisas (IoT, no acrônimo em inglês), produção inteligente e conectada, inteligência artificial, tecnologias de redes, biotecnologia e bioprocessos, nanotecnologia, materiais avançados e armazenamento de energia. Por meio dessas tecnologias haverá a introdução de interfaces avançadas na relação homem-máquina, deteç̧ão de fraudes, caracterização do perfil dos clientes e interação com clientes em vários níveis. (IEL, 2017; PwC, 2016a).

$\mathrm{Na}$ era da IoT, muitos dos objetos cotidianos estarão conectados à internet de alguma forma, isso será possível graças ao trabalho das tecnologias de identificação por radiofrequência (RFID - Radio-Frequency IDentification) e as redes de sensores que invisivelmente conectarão esses itens. A IoT será responsável por alavancar o fluxo de informações em cenários industriais e sociais, revolucionando a comunicação empresarial e privada (ANDRADE, 2017). Produção inteligente e conectada proporciona o controle virtual do processo produtivo, que passa a ser feito remotamente. $\mathrm{O}$ monitoramento da produção viabiliza a previsibilidade do processo produtivo, mediante a de processos de otimização, análise estatística, alertas sensoriais e modelagem preditiva. Assim, a empresa é capaz de identificar as falhas existentes com o objetivo de encontrar uma relação de causa e efeito no processo com maior agilidade (MARTIN, 2017a).

Por meio de inteligência artificial, big data e computação em nuvem há a possibilidade de identificação de falhas nos processos da empresa, ajuda a otimizar a qualidade da produção, economiza energia e torna mais eficiente a utilização de recursos na produção, por intermédio de um banco de dados capaz de ser acessado de qualquer lugar do mundo a partir de um dispositivo conectado à internet com informações em tempo real. Essas tecnologias permitem a criação de máquinas capazes de tomar decisões sem a intervenção humana (FREITAS, 2017). As tecnologias de rede são responsáveis pelo transporte de informações, interligando sistemas 
e soluções a níveis coorporativos, mediante o uso de plataformas de automação de processos centralizadas e integradas (SANTI, 2018). Há muita convergência entre as inovações de IoT, redes, inteligência artificial e big data, computação em nuvem e produção inteligente e conectada, sendo a última compreendida como a mais abrangente e agregadora das demais (DE PAULA, 2018).

A biotecnologia pode ser compreendida como a utilização de organismos, processos ou sistemas biológicos no meio industrial, por intermédio da combinação de engenharia genética, biologia celular e sistemas computacionais. A nanotecnologia, que faz parte do campo de atuação da biotecnologia, é compreendida como manipulação dos átomos para a produção de novos materiais em escala microscópica (FLORÊNCIO et. al, 2017, p.314). Os materiais avançados representam avanços sobre os materiais tradicionais, mediante a modificação ou adoção de materiais novos que geram melhor desempenho estrutural e funcional em uma ou mais características para sua aplicação comercial (IEL, 2017). Por fim, armazenamento de energia diz respeito à capacidade de armazenamento de energia através de processos químicos (ROGERS, 2018).

Em suma, os processos vêm se tornando cada vez mais complexos e utilizam-se de business analytics para acrescentar valor à cadeia produtiva. As possibilidades proporcionadas pela Indústria 4.0 geram recursos poderosos para aumentar a velocidade de computação, sensores e soluções para os negócios. Anteriormente a esta revolução, os processos de resolução de problemas contavam com uma baixa complexidade e eram focalizados na resolução de um único problema existente na totalidade dos sistemas. Atualmente, os sistemas criam soluções capazes de identificar áreas de maior ou menor desempenho, enquanto a modelagem preditiva encontra e quantifica padrões existentes nos dados utilizando-se de matemática avançada apta a prever os rendimentos futuros (KARLOVIĆ, 2017).

\section{OBSERVAÇÕES SOBRE O SETOR DE CELULOSE E PAPEL}

A celulose é um composto natural presente nos vegetais, de onde é extraída, podendo ser encontrada em toda a extensão das plantas, desde as raízes até os frutos e sementes. Tem forma alongada e pequeno diâmetro e são frequentemente denominadas de fibras. É um dos principais componentes das células vegetais. A lignina e hemiceluloses correspondem os outros componentes importantes das plantas. A preparação da pasta celulósica para papéis ou outros fins consiste na separação das fibras dos demais componentes da planta, especialmente a 
lignina, que atua ligando as células entre si e proporcionando rigidez à madeira (PIOTTO, 2003).

A celulose costuma ser classificada de acordo com o tipo de fibra, podendo ser curta ou longa, o processo de fabricação, entre químico, semiquímico e alto rendimento, e a destilação, sendo de mercado ou integrada. A fibra curta é originada de espécies arbóreas folhosas como o eucalipto e a longa de coníferas como o pinus, cada fibra tem propriedades que as tornam mais adequadas a certos tipos de papéis. O processo de fabricação determina o rendimento da madeira e a qualidade da celulose. A celulose de mercado é vendida para plantas de papel e a celulose integrada destina-se à produção de papel em uma planta anexa à produção da própria celulose. A celulose para produção de papéis compete diretamente com a fibra reciclada, feita a partir de aparas de papel. Porém, essas não são aptas a substituir completamente as fibras virgens, dado a degradação existente pela reciclagem contínua (BNDES, 2012).

Os principais tipos de celulose são kraft branqueada de fibra curta, kraft branqueada de fibra longa, kraft não branqueada e pasta mecânica. A celulose kraft branqueada de fibra curta é produzida por meio de processo químico e sua maior aplicação são papéis para imprimir e escrever (I\&E) e tissue, além de aplicações em papel-cartão. No Brasil, este tipo de celulose é proveniente do eucalipto, consistindo como o tipo mais produzido e no qual o país possui maior competitividade. A celulose do tipo kraft branqueada de fibra longa também é produzida por meio de processo químico, possibilitando a fabricação de um papel mais resistente, porém em razão do ciclo mais longo para o corte das coníferas é mais cara que que a kraft de fibra curta. Sua principal aplicação se verifica em embalagens e papéis tissue. A celulose kraft não branqueada é geralmente produzida a partir de fibra longa e destinada para papéis de embalagem. A pasta mecânica tem alto rendimento e, portanto, custo reduzido, mas possui qualidade inferior. É utilizada em papéis de I\&E e imprensa, além de aplicações em papelcartão. Ademais, existem pastas químicas de processo sulfito e pastas semimecânicas, porém estas possuem menor uso na indústria (BNDES, 2012).

O papel é majoritariamente constituído de celulose, que a matéria-prima mais importante no processo produtivo. Entretanto, são utilizadas matérias-primas não fibrosas dependendo do tipo e da utilização do papel. As principais matérias-primas não fibrosas são cargas de matéria de mineral e amido (responsáveis pela textura e pelo aspecto do papel), agentes de colagem (controle da penetração de líquidos), corantes e pigmentos (coloração do papel), além de inúmeros outros aditivos, como dispersantes, bactericidas, antiespumantes e resinas (PIOTTO, 2003). 
Os papeis tem um amplo espectro de utilização e são geralmente agrupados em papel imprensa, I\&E, papelão ondulado, papel-cartão e tissue. O papel imprensa é destinado, como o nome revela, à impressão de jornais e revistas. Os papéis I\&E costumam ser divididos em quatro subgrupo, dependendo do seu revestimento, podendo ser revestidos ou não revestidos, e da sua fabricação, podendo ser de celulose química ou de pasta mecânica. Essas características definam a qualidade e o valor do papel. A categoria de I\&E agrupada ao papel imprensa formam os papéis gráficos. O papelão ondulado é dirigido para a produção de embalagens e variam de qualidade conforme o insumo; quando fabricado com fibras virgens tem maior qualidade e resistência e quando fabricado com fibras recicladas tem qualidade inferior. O papel-cartão é fabricado a partir de múltiplas camadas, sendo utilizado predominantemente em embalagens de bens de consumo imediato. O papel kraft é uma mistura de celulose de fibra curta e fibra longa e pode servir como matéria prima para o papelão ondulado. O papelão ondulado, o papel-cartão e o papel kraft formam a categoria dos papéis de embalagem. Os papéis tissue são também conhecidos como sanitários e sua principal aplicação é o papel higiênico (BNDES, 2012).

A indústria brasileira de árvores plantadas é, atualmente, uma referência mundial por sua atuação pautada pela sustentabilidade, competitividade e inovação. As árvores plantadas são fonte de centenas de produtos e subprodutos presentes no cotidiano, exercem papel fundamental na mitigação dos efeitos das mudanças climáticas; e proveem diversos serviços ambientais, como a regulação dos ciclos hidrológicos, o controle da erosão e da qualidade do solo, a conservação da biodiversidade e a provisão de oxigênio para o planeta (IBÁ, 2017).

A celulose é uma commodity regulada a preços internacionais e configura um dos produtos mais competitivos do Brasil no exterior. A produção brasileira é majoritariamente direcionada à exportação, sendo que a maioria das fábricas brasileiras foi e continua sendo projetada com vistas à exportação (CORREA, 2014). O Brasil possui uma área de floresta plantada de 7,84 milhões de hectares, dos quais 5,7 milhões são florestas de eucalipto (IBÁ, 2017, p. 30). A produção do país em 2016 alcançou uma marca 18,8 milhões de toneladas, montante $8,1 \%$ superior ao ano anterior, destes $69 \%$ foram destinados à exportação. O Brasil é o segundo maior produtor mundial de celulose, sendo superado apenas pelos Estados Unidos, com uma produção de 48,5 milhões de toneladas (IBÁ, 2017).

O consumo de celulose está diretamente relacionado ao consumo de papel, que por sua vez está vinculado ao crescimento da população, à renda e à escolaridade, haja vista que quão maiores estes indicadores, maior o consumo de papéis do tipo I\&E e tissue. Para a indústria, quanto maior a produção, maior o fluxo de mercadorias e, consequentemente, maior o consumo 
de embalagens (CORREA, 2014). A produção brasileira de papel totalizou 10,3 milhões de toneladas em 2016, com apenas $20 \%$ tem como destino a exportação. O Brasil ocupou a oitava posição na produção de mundial de papel, atrás de China, Estados Unidos, Japão, Alemanha, Índia, Coreia do Sul e Canadá. O maior destes players, a China, produziu 111,2 milhões de toneladas em 2016 (IBÁ, 2017).

Segundo Berg e Lingqvist (2017), em 2015, os produtos de papel gráfico tiveram uma queda na demanda mundial. No entanto, a indústria de $\mathrm{P} \& \mathrm{C}$ está crescendo, mesmo que em um ritmo mais lento que anteriormente, com outros produtos preenchendo o vácuo deixado pela queda dos papéis gráficos. O segmento de embalagens está se expandindo mundialmente, bem como os papéis tissue. Além disso, a aplicação de celulose no setor têxtil é crescente, mesmo que este configure um mercado pequeno (Gráfico 1). No Brasil, entre 2015 e 2016, apenas os papéis tissue e I\&E tiveram um aumento na sua produção, sendo 2,9\% e 0,6\%, respectivamente. O papel-cartão acumulou uma queda de $-3,6 \%$, os papéis imprensa tiveram um decréscimo de $2 \%$, embalagens sofreram uma perda de $0,6 \%$, outros papéis registraram uma diminuição de $1,8 \%$, o que resultou em uma queda de $0,2 \%$ na produção total brasileira de papéis (IBÁ, 2017).

\section{Gráfico 1: A indústria mundial de papel, 1992-2015 (milhões de toneladas)}

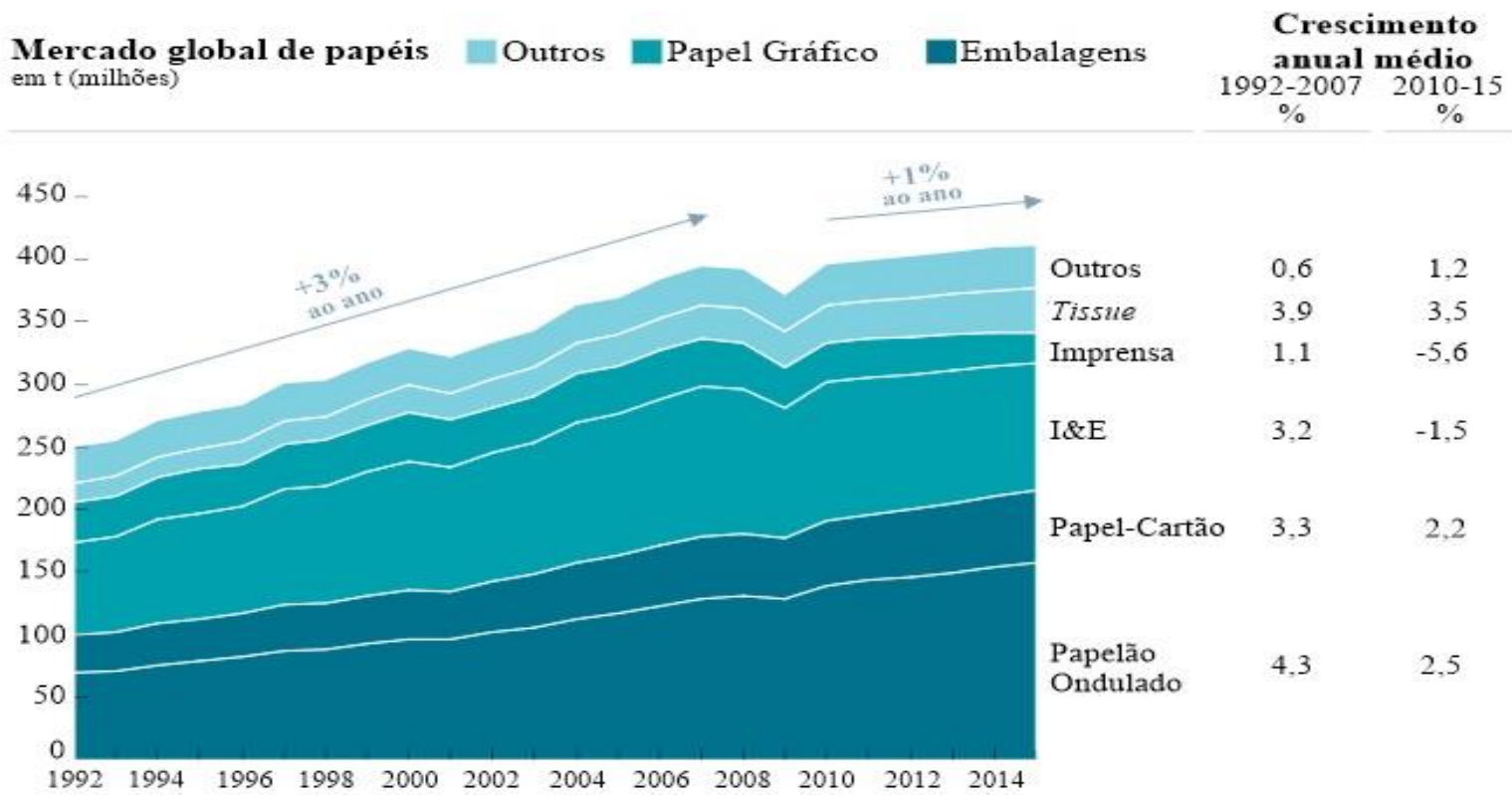

Fonte: BERG \& LINGQVIST (2017)

As empresas do setor terão uma década de crescimento para produtos de $\mathrm{P} \& \mathrm{C}$ na próxima década, mesmo que os papéis gráficos continuem experimentando uma queda na 
demanda. No entanto, essa retração deve ser compensada pelo crescimento da demanda por embalagens - pela indústria e por consumidores finais - e por papéis tissue. O incremento da demanda de embalagens cresce ancorado no e-commerce e o os papéis tissue se baseiam no progresso de países subdesenvolvidos que passam a desfrutar de melhores condições sanitárias. Além disso, a demanda por celulose segue a perspectiva de crescimento da economia, mesmo que alguns segmentos cresçam com mais intensidade do que outros. Além disso, o aumento da demanda por P\&C na economia chinesa representa um forte impacto no setor (BERG \& LINGQVIST, 2017). A Figura 1 demonstra o crescimento esperado da demanda no período 2016-2021 para os segmentos de papel tissue, papéis gráficos, embalagens e celulose kraft de fibra curta e fibra longa. Os papéis para impressão e escrever e de imprensa representam os piores resultados para o setor, os papéis tissue, kraft, papel-cartão e papelão ondulado terão crescimento em todo o globo nos próximos anos, demonstrando uma mudança no padrão de consumo do setor.

Figura 1: Crescimento anual esperado da demanda de papel e celulose por regiões e países selecionados, 2016-2021 (\%)

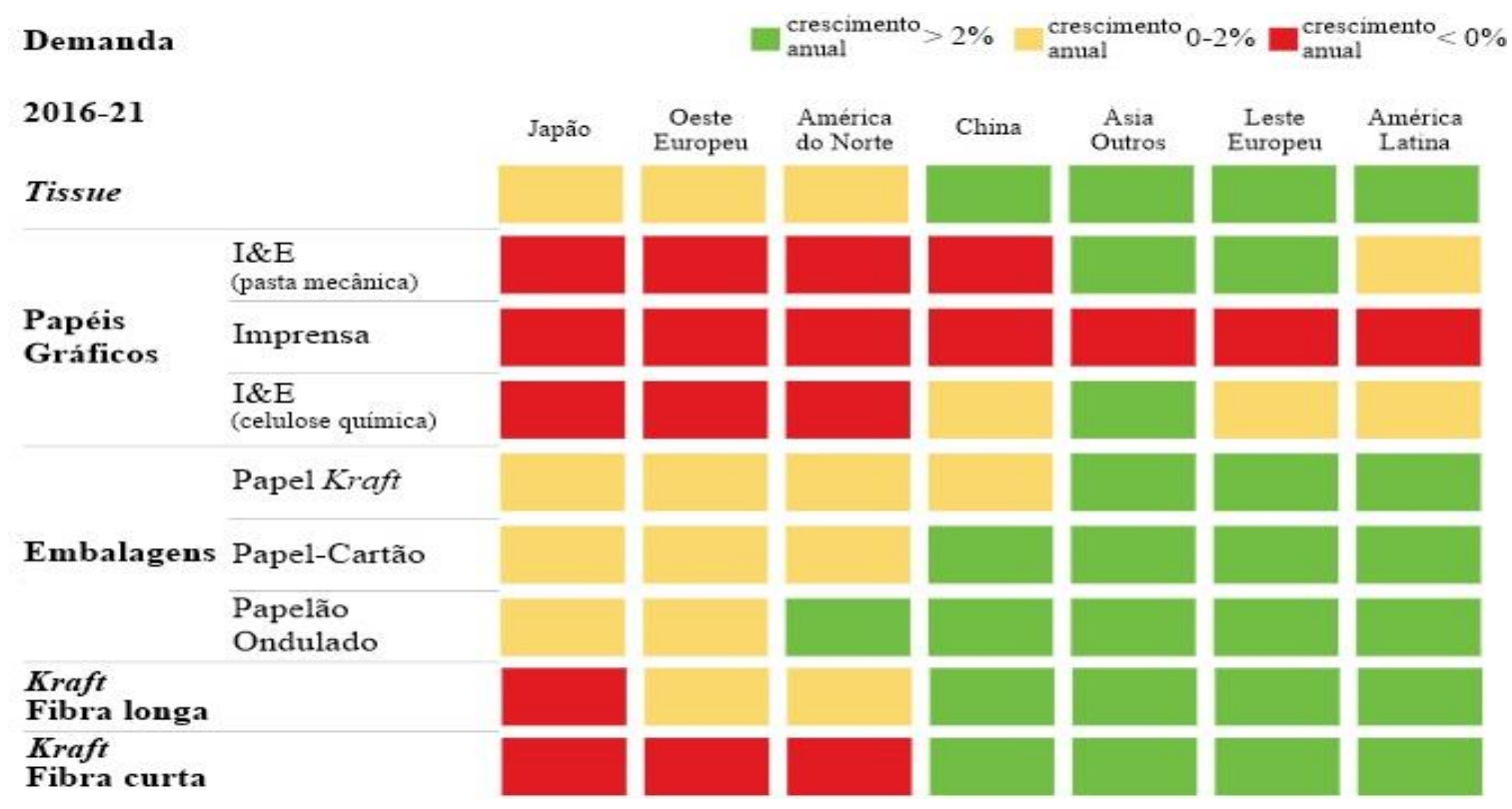

Fonte: BERG \& LINGQVIST (2017) 


\section{O IMPACTO DA INDÚSTRIA 4.0 SOBRE O SETOR DE PAPEL E CELULOSE}

\subsection{UMA VISÃO GERAL}

No futuro, a indústria de P\&C será organizada em "ecossistemas", que substituirão os processos e funções individuais fabris. A cadeia de valor será formada de clusters interconectados, que continuamente enviarão e receberão informações um do outro por intermédio de computação em nuvem e sistemas de big data. Haverá um grande volume de informações capazes de alcançar todos os participantes da cadeia de valor. Da mesma forma que a automação tornou o processo manual mais eficiente, as novas tecnologias automatizarão trabalho repetitivo de modo que o foco se torne a análise a tomada de decisão (CEPI, 2015).

Por intermédio da Indústria 4.0 haverá redução do contato entre homens e máquinas, gerando uma maior segurança nas fábricas. Além disso, as possibilidades de manutenção preditiva mais eficiente aumentarão o tempo de vida útil dos ativos, bem como maior produtividade, a partir de um sensoriamento, virtual e real, nas fabricantes de P\&C. Todas as tecnologias utilizadas no cotidiano, como GPS, reconhecimento de voz e gestos e análise computacional, já são utilizados na indústria para coleta, sincronização e visualização de dados, mas essa tecnologia já vem se tornando superada. A expectativa dos clientes é obter dados mais práticos e mais profundos como previsões e recomendações baseadas na experiência das máquinas e da fabricação de papel para auxiliar a tomada de decisão e otimização de operações (MARTIN, 2017a).

Os bens de capital para a produção de celulose tem um alto nível de automação. A manutenção preventiva de sensores e scanners, acompanhada do processo de controle das máquinas e do sistema de controle de qualidade possibilitam avaliar a produtividade de todo o sistema produtivo. Além disso, controles automáticos se adaptam constantemente às condições e objetivos produtivos e são ativados por de softwares especializados no ciclo de produção da celulose. O processo de registro de informações transmitidas pelos sensores permite que o sistema se adapte aos diferentes estágios da produção, estabelecendo parâmetros a serem executados durante todo o processo produtivo (KARLOVIĆ, 2017).

A partir da IoT, a indústria vem desenvolvendo a capacidade de capturar e compartilhar dados e informações de máquinas e processos de produção de celulose, papel e energia para usá-los em prol do cliente. Todavia, um pré-requisito para se beneficiar dessa ideia a conexão e uso dos dados de forma contínua para embasar as decisões tomadas, seja para fazer diagnóstico de máquinas, direcionar a produção, buscar a otimização de custos ou, ainda, de 
toda a cadeia de valor (MARTIN, 2017a). Por meio da produção inteligente e conectada haverá a massificação do acesso à informação, que será facilitará a tomada de decisões, sendo que as empresas mudarão a forma é que oferecida o suporte e entrega de serviços aos clientes. Outros conceitos, como virtualização e descentralização, também colaborarão para otimizar a operação das plantas em aspectos que compreenderão desde tratamento de água e utilização de energia até a nova forma de processamento das informações.

A automação e troca de dados dos dispositivos de rede controlados por sistemas de inteligência artificial combinados com manipulação dos dados por computação em nuvem proporcionará um aumento de produtividade e de valor adicionado na produção (KARLOVIĆ, 2017). O big data permite a extração de informações que colaboram no controle do processo industrial até a tomada de decisões gerenciais estratégicas. Existe uma série de tecnologias que são adotadas para tomadas de decisão em tempo real, como modelagem de dados com técnicas avançadas, como redes neurais artificiais e árvores de decisão, sensores virtuais e mineração de dados, usando técnicas de clusterização para identificar os melhores cenários de operação (MARTIN, 2017a). O volume de dados gerado na fabricação de papel, ao longo de extensos períodos, não pode ser processado com eficácia utilizando-se métodos manuais, no entanto por intermédio do big data e computação em nuvem é possível realizar a análise de grandes quantidades de dados.

A conectividade proporcionada pelas tecnologias de redes possibilitam a interconexão de sistemas e uma maior gama de soluções, enquanto gera uma grande quantidade de informações, que expostas, podem representar ataques cibernéticos às indústrias. Na indústria de $\mathrm{P} \& \mathrm{C}$, a instalação de um projeto de segurança cibernética envolve a tecnologia de automação e a política de segurança de tecnologia da informação (TI). A segurança aplicada aos sistemas de controles industriais são um processo dinâmico, no qual as áreas de tecnologia de automação e TI avaliam rotineiramente os riscos presentes e já indicam as melhorias (SANTI, 2018).

A presença massiva de internet no processo produtivo leva a uma geração de dados para ser estocada, processada e apresentada de uma maneira energeticamente sustentável e eficiente. Além disso, há a exigência de data centers eficazes. Para isso, surgiu o conceito de Green IoT, que pode ser definido como os procedimentos adotados pela IoT para a redução do efeito estufa provocado pela adoção dessas tecnologias no curto prazo. Ainda, é esperado que os processos relacionados ao Green IoT possam reduzir a pegada de carbono relacionados à IoT. O ciclo de vida do processo produtivo será focalizado em um design, produção, utilização e eliminação sustentável para haver um menor impacto sobre o meio ambiente (SHAIKH et al., 2017). 
Genericamente, as empresas do setor de P\&C têm se comprometido com a sustentabilidade em seus negócios, sendo os principais problemas identificados, além das mudanças climáticas e do efeito estufa, a eficiência energética, florestas sustentáveis, preservação da biodiversidade, gestão dos recursos hídricos, desperdício e reciclagem (JONES \& COMFORT, 2017).

As tecnologias de biotecnologias e bioprocessos são fundamentais ao setor de $\mathrm{P} \& \mathrm{C}$, dado que as fábricas são biorrefinarias. Além disso, a aplicação de enzimas abre uma nova possibilidade nos processos químicos presentes na produção. As nanoestruturas, que são derivadas de biotecnologia, indicam inúmeras oportunidades ao setor. A nanocelulose gera oportunidades internas, no âmbito do desenvolvimento de produtos no portfólio, e oportunidade externa, a partir de produtos inovadores oferecidos ao mercado complementando a linha de produção atual (DE PAULA, 2018). A partir da implementação de materiais avançados na produção haverá uma transformação nos recursos na indústria de papel, cuja principal característica será uma produção limpa, circular e ecológica (HUANG, 2017). A celulose é um compósito com a habilidade química de isolamento térmico e armazenamento de energia, de forma que as florestas são meios naturais de armazenamento de energia (COUTINHO, 2006).

A um nível mundial, o setor planeja investir em digitalização uma média de $4 \%$ das receitas anuais nos próximos cinco anos. Além disso, a expectativa é que o setor alcance um alto nível de digitalização e integração das suas operações, sendo que 38\% das empresas atuais já alcançou um alto grau de e $72 \%$ esperam alcançar um nível alto em cinco anos. Essas tecnologias estão deixando de ser um diferencial para algo essencial na indústria, com grande importância para lidar com os desafios atuais da indústria. Assim, ao adotar essas tecnologias, as máquinas serão capazes de operar com maior flexibilidade, maior capacidade de utilização com uma reação mais rápida dos processos, fazendo com que aumente a lucratividade e diminua a utilização de capital humano (PwC, 2016b).

Segundo Martin (2017a, pg. 57), existem economias significativas de matéria prima, energia, produção, rendimento e qualidade mediante aos processos de otimização que a indústria vem passando. As perspectivas são de um aumento de $20 \%$ no tempo de vida dos equipamentos consumíveis, redução de $15 \%$ e $20 \%$ no consumo de energia e matérias primas, respectivamente, num cenário no qual a produção estará 15\% mais elevada. 


\subsection{A VISÃO DAS EMPRESAS BRASILEIRAS}

Esta seção se baseia, principalmente, em recente relatório de pesquisa de um dos autores deste artigo (DE PAULA, 2018). A indústria florestal, de celulose e papel é constituída por três etapas diferentes em termos de características produtivas. Enquanto que nas atividades industriais (celulose e papel), os desenvolvimentos podem ocorrer num curto período (meses), na atividade florestal a referência situa-se na escala de décadas para obtenção dos resultados decorrentes do desenvolvimento e homologação de um novo produto. Além disso, os requerimentos quanto à escala produtiva e o grau de modernização são distintos nas três etapas.

Para observar a realidade das empresas brasileiras, optou-se pelo uso de um questionário. Deste modo, é importante enfatizar que as respostas dos questionários retratam percepções das empresas e, como tal, não são isentas de vieses. A amostra é composta de companhias de grande porte e as respostas refletem a realidade de tais companhias. Uma é integrada da floresta ao papel e a outra focalizada na atividade florestal e na fabricação de celulose.

Na indústria de celulose, a adoção do cluster de IoT não é maciça e sua difusão atual é considerada baixa/moderada, com a expectativa de uma difusão alta em cinco anos, fazendo parte da rotina das pessoas e organizações. A produção inteligente e conectada apresenta iniciativas em países desenvolvidos, contudo não é disseminada, especialmente em economias em desenvolvimento. Todavia, para o setor florestal, a difusão e o impacto já são relativamente moderados e devem permanecer assim até 2022. A disseminação de inteligência artificial, computação cognitiva, redes neurais e análises preditivas, entre outras ferramentas, ainda é muito pequena na indústria mundial de celulose frente às possibilidades vislumbradas. Do mesmo modo, a análise de informações através de big data analytics é limitada. Mesmo em 2022, a expectativa é que a difusão do cluster seja moderada. A adesão atual da tecnologia de redes é moderada/alta, entretanto sua intensidade de adoção depende da região das plantas, o que indica dificuldades para a plena adoção. Ademais, as redes são utilizadas dentro de uma mesma linha de produção, mesmo que não entre linhas diferentes. No setor florestal, a difusão ainda é baixa e o seu impacto é moderado. Em 2022, espera-se que a difusão das redes rápidas e seguras na indústria de celulose seja alta. Por fim, IoT, redes, IA, big data e computação em nuvem e produção inteligente terão alta difusão em 2027.

O cluster de biotecnologia e bioprocessos têm uma difusão moderada no setor florestal e baixa na área industrial. Mesmo se tratando de biorrefinarias, as fábricas de celulose não 
empregam completamente a ideia de extrair da base florestal todos os produtos que poderiam contribuir para a redução da participação dos produtos não sustentáveis no cotidiano. Até 2022 espera-se que ocorram melhorias e a difusão se torne moderada, em especial na edição de genomas para culturas vegetais. Os materiais nanoestruturados apresentam baixa difusão e impacto para o setor. A maior operação em nanocelulose apresenta escala anual de duas toneladas e encontra-se instalada no Brasil. Em 2022, após a solução das questões toxicológicas inerentes ao produto nano, espera-se que a difusão seja moderada. Os materiais avançados encontram-se em escala piloto com poucos projetos. Os compósitos, principais representantes da categoria, tem adoção e impacto reduzidos. No entanto, a perspectiva é que cheguem a um nível moderado nos próximos cinco anos. Uma vez que as florestas são grandes armazenadores de energia do setor, as tecnologias de armazenamento de energia apresentam baixo impacto. Porém, as produtoras não integradas de papel não se beneficiam da geração de energia propiciada pela produção de celulose. Para 2022, a difusão deve ser baixa e, em 2027, moderada/alta.

O Quadro 1 sistematiza a percepção predominante acerca da difusão global dos clusters tecnológicos no setor em três momentos: atualmente, em 2022 e em 2027. O Quadro 2 aponta para uma convergência entre o grau de difusão e a intensidade do impacto em 2027.

Quadro 1: Percepção das empresas consultadas quanto à difusão das tecnologias disruptivas na indústria mundial de celulose - 2017, 2022 e 2027

\begin{tabular}{cccc}
\hline Tecnologias & 2017 & 2022 & 2027 \\
\hline Internet das Coisas & Baixa/Moderada & Alta & Alta \\
Produção inteligente e conectada & Baixa & Moderada & Alta \\
Inteligência artificial, big data e computação em nuvem & Baixa & Moderada & Alta \\
Redes de comunicação rápidas e seguras & Moderada/Alta & Alta & Alta \\
Biotecnologia e Bioprocessos & Baixa/Moderada & Moderada & Alta \\
Materiais nanoestruturados & Baixa & Moderada & Alta \\
Materiais avançados & Baixa & Moderada & Alta \\
Armazenamento de energia & Baixa & Baixa & Moderada/Alta \\
\hline
\end{tabular}

Fonte: DE PAULA (2018) 
Quadro 2: Percepção das empresas consultadas quanto à difusão e intensidade do impacto das tecnologias disruptivas na indústria mundial de celulose $\mathbf{- 2 0 2 7}$

\begin{tabular}{ccc}
\hline Tecnologias & Difusão & Impacto \\
\hline Internet das Coisas & Alta & Moderado \\
Produção inteligente e conectada & Alta & Alto \\
Inteligência artificial, big data e computação em nuvem & Alta & Moderado \\
Redes de comunicação rápidas e seguras & Alta & Alto \\
Biotecnologia e Bioprocessos & Alta & Alto \\
Materiais nanoestruturados & Alta & Alto \\
Materiais avançados & Alta & Alto \\
Armazenamento de energia & Moderada/Alta & Alto \\
\hline
\end{tabular}

Fonte: DE PAULA (2018)

Para uma fabricante de celulose, os clusters tecnológicos mais importantes são tecnologias de redes de comunicação rápidas e seguras, materiais avançados, materiais nanoestruturados e armazenamento de energia. Para a outra, são processos inteligentes e conectados e bioprocessos e biotecnologias avançadas.

Os motivos para escolha das tecnologias de redes de comunicação rápidas e seguras partem de questões de segurança da informação, que podem paralisar ou inviabilizar negócios ou países. Os materiais avançados, por sua vez, se baseiam em questões de sustentabilidade que demandarão produtos de fontes verdes. Novas aplicações e adoção de produtos de melhor qualidade exigirão produtos de nanotecnologia. Apesar da aparente dificuldade de aplicação em escala, o armazenamento de energia pode levar à reformulação dos padrões de concorrência e modelos de negócio, em especial ligados às fontes de energia não renováveis.

Os processos inteligentes e conectados propiciarão uma produção rápida, automatizada e de alta qualidade, com novas operações logísticas automatizadas e otimizadas. Os bioprocessos e biotecnologias estão ligados à redução de gases de efeito estufa e da pegada de carbono, cuja base florestal é a fonte de inúmeros produtos sustentáveis.

Uma das firmas apresentou uma visão detalhada dos maiores benefícios de cada cluster tecnológico, enquanto a outra empresa preferiu indicar uma abordagem agregada. Segundo esta última, as vantagens do IoT são a agilidade, redução de custos de produção e melhoria na qualidade de vidas pessoas. As tecnologias de redes proporcionam acessibilidade com qualidade de mais pessoas em pontos mais remotos a informações em tempo real. Inteligência artificial, big data e computação em nuvem são responsáveis pela redução de custos em TI e ampliação de análises complexas. Processos inteligentes e conectados permitem a redução de 
custos. Materiais avançados propiciam produtos mais sustentáveis e aplicações diversas, enquanto que materiais nanoestruturados geram novos produtos e aplicações. O armazenamento de energia possibilitam energia sustentável e de menor custo. Por fim, a biotecnologia e bioprocessos tem como benefício a maior produção florestal e adaptação a efeitos relacionados às mudanças climáticas.

A mesma empresa também discutiu as principais barreias por clusters. As tecnologias de redes defrontam com ataques cibernéticos. O principal empecilho para processos inteligentes e conectados é a acessibilidade e aplicabilidade da tecnologia. Este problema também é presente para inteligência artificial. Materiais avançados sofrem da pressão de preços dos produtos da indústria do petróleo. Biotecnologias e materiais nanoestruturados podem enfrentam barreiras regulatórias, bem como o armazenamento de energia, todavia este ainda possui a necessidade de altos de investimentos ao seu desenvolvimento. IoT é o único cluster sem obstáculos relevantes. Pode-se verificar que a intensidade entre os benefícios são mais relevantes que a intensidade das barreiras, o que explicaria a elevada difusão dos clusters em 2027.

Os obstáculos mencionados pela outra empresa foram investimentos para instalação de sensores e rede interna dentro da unidade produtiva, principalmente para as mais antigas com mais de cinco a dez anos de operação, segurança da informação, padronização dos protocolos de comunicação, infraestrutura e disponibilidade de mão de obra especializada e de fornecedores para atender o aumento da demanda.

Na percepção das empresas consultadas, o setor de celulose se aproxima das melhores práticas mundiais. Uma das companhias afirmou que com relação a setor florestal, é indiscutível a superioridade brasileira da produtividade florestal em relação aos competidores internacionais, mesmo sem estar utilizando na sua plenitude as TI e comunicação disponíveis para o manejo florestal. No segmento industrial de $\mathrm{P} \& \mathrm{C}$, como os fornecedores de equipamentos e tecnologia do segmento analisado são globalizados, os novos investimentos estão equalizados frente aos competidores internacionais. $\mathrm{O}$ desafio é viabilizar a atualização tecnológica das unidades mais antigas e menores. A outra empresa, embora menos otimista quanto à difusão dos clusters tecnológicos, destacou o papel de proeminência para nano e biotecnologia.

As duas firmas consultadas se enxergam na fronteira quanto à adoção das melhores práticas no Brasil. Uma delas afirmou estar muito bem posicionada, em relação a vários desenvolvimentos, com destaque para algumas aplicações que já são realidade, como: IoT (e 
Internet das Árvores); big data e análise preditiva; desenvolvimento em biomateriais e biocompósitos, nanocelulose e nanomateriais, biotecnologia arbórea e realidade aumentada e operação industrial e florestal autônoma. Na mesma direção, a outra companhia comentou que seus últimos investimentos utilizaram tecnologias de última geração em tecnologia de informação e comunicação. Além disso, comentou que o maior desafio é a atualização das unidades mais antigas em operação.

\section{CONCLUSÃO}

A revolução proposta pela Indústria 4.0 ao setor de celulose e papel é mais complexa e dinâmica do que qualquer experiência anterior. Um dos pré-requisitos para se beneficiar dessa ideia é a conexão e uso dos dados de forma contínua para embasar as decisões tomadas, seja para fazer diagnóstico de máquinas, direcionar a produção, buscar a otimização de custos ou, ainda, de toda a cadeia de valor (MARTIN, 2017a). Impressão 3D em embalagens, análise preditiva e integração de chips RFID são exemplos de tecnologias que já estão sendo integradas no setor. Essas inovações oferecem novas oportunidades à melhoria da integração produtiva e da produtividade. $\mathrm{O}$ uso de drones nas florestas vem crescendo e tem o potencial de monitorar as florestas remotamente. Até o uso de veículos autônomos é considerado para o transporte de materiais entre as plantas industriais (PwC, 2016c).

Com a digitalização do processo produtivo, novos papéis e responsabilidades serão criados. Além disso, funções operacionais poderão ser diminuídas ao mínimo, dado que as máquinas serão capazes de tomar decisões sem interação humana. Muitas oportunidades existem a respeito do futuro da Indústria 4.0 no setor de P\&C. As tecnologias da Indústria 4.0 permitirão o acesso à informação e facilitarão a tomada de decisões, as empresas mudarão a forma é que oferecida o suporte e entrega de serviços aos clientes. Outros conceitos, como virtualização e descentralização, também colaborarão para otimizar a operação das plantas em aspectos que compreenderão desde tratamento de água e utilização de energia até a nova forma de processamento das informações.

Entre os desafios envolvidos na Indústria 4.0, há a necessidade de mudança do perfil do administrador e do trabalhador, que se tornará em um "gestor tecnológico", preocupado com o controle dos riscos e consciente dos benefícios da tecnologia e da permanência da mesma. Investimentos em treinamento, capacitação, novas tecnologias, novos modelos construtivos serão ações estratégicas para a competitividade das empresas (MARTIN, 2017b). Além disso, o setor é intensivo em capital e tem um grande período de maturação de suas plantas, e 
consequentemente leva muitos anos antes que as inovações sejam completamente adotadas na indústria (ROGERS, 2018).

De um modo geral, os impactos apontados parecem insuficientes para alterar radicalmente os modelos de negócios do segmento, tendendo sobretudo a reforçar estratégias competitivas predominantes (DE PAULA, 2018, p. 62). Ademais, as oportunidades digitalização, integração e automação permitem as empresas acrescentarem valor a si e às suas cadeias de valor, de modo que proporciona um aumento de produtividade. As possibilidades de crescimento a partir da Indústria 4.0 aumentam a medida que as firmas procuram se manter relevantes na era da infraestrutura inteligente e digitalmente conectada. 


\section{REFERÊNCIAS}

ANDRADE, P. S. A. M. A Quarta Revolução Industrial e sua relação com a produtividade atual: uma revisão da literatura. Trabalho de conclusão de curso (Bacharelado em Administração) — Universidade de Brasília, Brasília, 2017.

BANCO NACIONAL DE DESENVOLVIMENTO ECONÔMICO E SOCIAL. BNDES 60 anos: perspectivas setoriais. Rio de Janeiro: Banco Nacional de Desenvolvimento Econômico e Social. v.1, p. 334-381, 2012.

BERG, P; LINGQVIST, O. Pulp, paper, and packaging in the next decade: Transformational change. McKinsey\&Company: Paper and Forest Products. 2017.

CEPI. Paper Industry 4.0: What Digital Can Do For The Paper Industry. Brussels: Confederation of European Paper Industries (CEPI). 2015.

CORREA, D. V. G. Celulose: logística e distribuição internacional. SENAI-SP Editora, São Paulo, 2014.

COUTINHO, J. A. P. Materiais de mudança de fase para isolamento térmico e armazenamento de energia. Engenharia Química, p. 2-7 2006.

DE PAUlA, G. M. Nota Técnica do Sistema Produtivo Insumos Básicos e Foco Setorial Siderurgia. Relatório do Projeto Indústria 2027: Riscos e Oportunidades para o Brasil Diante de Inovações Disruptivas. Rio de Janeiro: IE-UFRJ; Campinas: IE-UNICAMP, 2017.

FLORÊNCIO, M. N. S. et. al. Prospecção Tecnológica: Um Estudo Sobre os Depósitos de Patentes em Nanobiotecnologia. Cadernos de Prospecção - Salvador. v. 10, n. 2, p.315-326, 2017

FREITAS, A. A. A internet das coisas e seus efeitos na indústria 4.0. Trabalho de conclusão de curso (Bacharelado em Sistemas de Computação) — Universidade Federal Fluminense, Rio de Janeiro, 2017.

HUANG, J. Sustainable Development of Green Paper Packaging. Environment and Pollution. v. 6, n. 2, p. 1-5, 2017.

IBÁ. Relatório 2017. São: Indústria Brasileira de Árvores (Ibá). 2017.

IEL - INSTITUTO EUVALDO LODI; NC - NÚCLEO CENTRAL. Mapa de clusters tecnológicos e tecnologias relevantes para competitividade de sistemas produtivos. Brasília, 
DF: IEL/NC, 2017. Disponível em: <http://www.portaldaindustria.com.br/cni/canais/industria2027/publicacoes/>.

JONES, P; COMFORT, D. The Forest, Paper And Packaging Industry And Sustainability. International Journal Of Sales, Retailing And Marketing. v.6 n.1, p.3-21, 2017.

KARLOVIĆ, I. Technologies For Using Big Data In The Paper And Printing Industry. Journal Of Print And Media Technology. Slovenia. v.6, n.2, p. 75-84, 2017.

MARTIN, C. Indústria 4.0 Aponta Caminhos para Chegar à Fábrica Do Futuro: Máquinas Inteligentes e Comunicação Entre Processos Serão Novo Padrão dos Parques Fabris de Celulose e Papel. O Papel: Revista Mensal de Tecnologia em Celulose e Papel. v.78, n. 4, p. 54-62, $2017 \mathrm{a}$.

MARTIN, C. A Indústria do Futuro Sob o Olhar dos Fornecedores. O Papel: Revista Mensal de Tecnologia em Celulose e Papel. v.78, n. 12, p.68-73, $2017 \mathrm{~b}$.

PIOTTO, Z. C. Eco-eficiência na Indústria de Celulose e Papel - Estudo de Caso. Tese (Doutorado em Engenharia Hidráulica e Sanitária) - Universidade de São Paulo, São Paulo, 2003.

PWC. Indústria 4.0: Digitalização como vantagem competitiva no Brasil. São Paulo: PricewaterhouseCoopers (PWC). 2016a.

PWC. Industry 4.0: Building the digital enterprise. Munich: PricewaterhouseCoopers (PWC). $2016 b$.

PWC. Industry 4.0: Building the digital enterprise; Forest, paper and packaging key findings. Munich: PricewaterhouseCoopers (PWC). 2016c.

ROGERS, J. G. Paper making in a low carbon economy. AIMS Energy. v.6, n.1, p. 187-202, 2018.

SANTI, T. Segurança Cibernética na Indústria 4.0. O Papel: Revista Mensal de Tecnologia em Celulose e Papel. v.79, n. 2, p. 68-69, fevereiro 2017.

SANTOS, B. P; ALBERTO, A; LIMA, T. D. F. M; CHARRUA-SANTOS, F. M. B. Indústria 4.0: Desafios e Oportunidades. Revista Produção e Desenvolvimento. v.4, n.1, p.111-124, 2018.

SHAIKH, F. K; ZEADALLY, S; EXPOSITO, E. Enabling Technologies for Green Internet of Things. IEEE Systems Journal. v.11, n.2, p. 983-994, 2017. 